\title{
A Study on the Preparation of the Eco-friendly Carbon Fibers- Reinforced Composites
}

\author{
Kyeong-Eun Choi ${ }^{1, \star}$ and Min-Kang Seo ${ }^{2}$ \\ ${ }^{1}$ Department of Practical Arts Education, Jeonju National University of Education, Jeonju 560-757, Korea \\ ${ }^{2}$ Jeonju Institute of Machinery and Carbon Composites, Jeonju 561-841, Korea
}

\section{Article Info}

Received 1 December 2012 Accepted 11 January 2013

*Corresponding Author

E-mail: kechoi@jnue.kr

\section{Open Access}

DOI: http://dx.doi.org/

10.5714/CL.2012.14.1.058

This is an Open Access article distributed under the terms of the Creative Commons Attribution Non-Commercial License (http://creativecommons.org/licenses/ by-nc/3.0/) which permits unrestricted non-commercial use, distribution, and reproduction in any medium, provided the original work is properly cited.

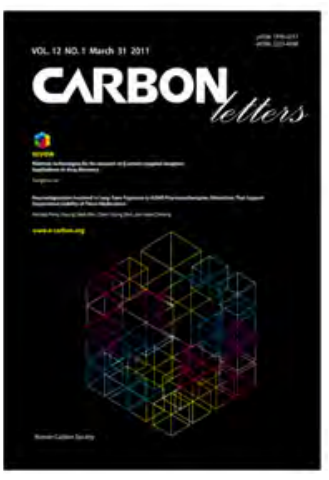

http://carbonlett.org

pISSN: 1976-4251

elSSN: 2233-4998

Copyright $\odot$ Korean Carbon Society

\begin{abstract}
In this work, the effect of catalysts on the mechanical properties of carbon fibers-reinforced epoxy matrix composites cured by cationic latent thermal catalysts, i.e., N-benzylpyrazinium hexafluoroantimonate (BPH) was studied. Differential scanning calorimetry was executed for thermal characterization of the epoxy matrix system. Mechanical interfacial properties of the composites were studied by interlaminar shear strength (ILSS), critical stress intensity factor $\left(\mathrm{K}_{\mathrm{IC}}\right)$, and specific fracture energy $\left(\mathrm{G}_{\mathrm{IC}}\right)$. As a result, the conversion of neat epoxy matrix cured by BPH was higher than that of one cured by diaminodiphenyl methane (DDM). The ILSS, $\mathrm{K}_{\mathrm{IC}}, \mathrm{G}_{\mathrm{IC}}$, and impact strength of the composites cured by BPH were also superior to those of the composites cured by DDM. This was probably the consequence of the effect of the substituted benzene group of BPH catalyst, resulting in an increase in the cross-link density and structural stability of the composites studied.
\end{abstract}

Key words: carbon fibers-reinforced composites, catalyst, N-benzylpyrazinium hexafluoroantimonate, mechanical interfacial properties

\section{Introduction}

Generally, a curing agent for epoxy matrix resins involves the use of a cross-linker such as amine and diacid anhydride. However, they have some problems, such as the toxicity of amine, combined with low heat resistance and the deterioration of mechanical properties at high temperature or at high humidity, which requires energy consumption, resulting in a long curing process [1]. Therefore, catalytic curing agents of epoxy matrix resins have been studied as substitutes for the amine or anhydride agents [2,3].

A cationic catalyst is generally used as a complex, such as $\mathrm{BF}_{3}$-ether, $\mathrm{BF}_{3}$-amine, or $\mathrm{SbF}_{6}$-epoxide. These complexes overcome the disadvantage of excessively rapid gelation, human toxicity, high hygroscopicity, and light instability [4]. Particularly, development of latent catalysts for cationic polymerization is desirable for enhancement of both the pot-life and handling of thermosetting resins $[5,6]$. Among them, N-benzylpyrazinium salt has been shown to be an excellent latent thermal initiator for epoxy matrix resins $[7,8]$. This initiator is not hygroscopic and dissolves readily in epoxy matrix resins and exhibits a longer pot-life than the more commonly used $\mathrm{BF}_{3}-4-$ methoxyaniline complex [9].

Polymeric composites, such as carbon fibers/epoxy resins and carbon fibers/PEEK systems are now being used in numerous aerospace, marine, and recreational applications. The particular composites chosen depend on the application. Epoxy resins have proved to be the most versatile in this respect as the resin itself can be cross-linked with a number of different amines, anhydrides, and acids. They can also react with many other polymer substances [1012]. The properties of these composites, however, are governed not only by the properties of reinforcing materials, such as carbon fibers, glass fibers, aramid fibers, and so on, but also by the curing agents for the matrix resins. 


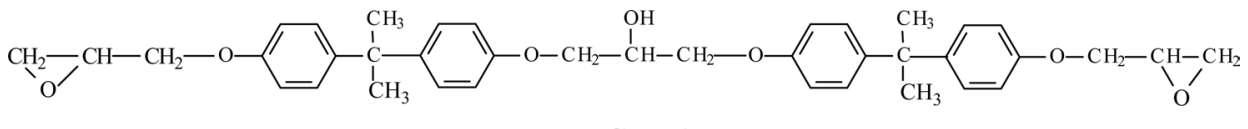

DGEBA

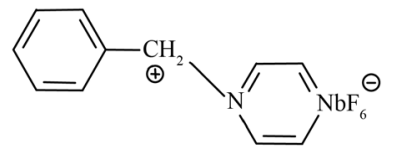

$\mathrm{BPH}$

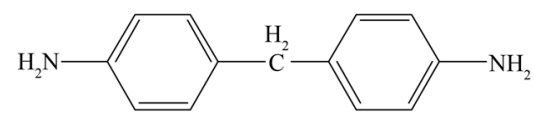

DDM

Fig. 1. Chemical structures of DGEBA, BPH, and DDM. DGEBA: diglycidylether of bisphenol-A, BPH: N-benzylpyrazinium hexafluoroantimonate, DDM: diaminodiphenyl methane.

In this work, the curing agent, i.e., N-benzylpyrazinium hexafluoroantimonate $(\mathrm{BPH})$, was used as a cationic latent thermal catalyst to improve the properties being demanded of carbon fibers-reinforced epoxy matrix composites, and to be an ecofriendly process as well. And the effect of the above catalyst on the mechanical properties of the composites was investigated by interlaminar shear strength (ILSS), critical stress intensity factor $\left(\mathrm{K}_{\mathrm{IC}}\right)$, specific fracture energy $\left(\mathrm{G}_{\mathrm{IC}}\right)$, and impact tests.

\section{Experimental}

\subsection{Materials and sample preparation}

The carbon fibers used in this study were untreated and unsized PAN-based high-strength fibers, TZ-307 (12 K monofilaments), manufactured by Taekwang Co. of Korea. The average diameter of these carbon fibers was approximately 7 $\mathrm{m}$, and typical tensile modulus and strength were about 245 and $3.5 \mathrm{GPa}$, respectively. Epoxy matrix resins used in this study were diglycidylether of bisphenol-A (DGEBA, YD128 supplied from Kukdo Chem. Co. of Korea). The cationic latent thermal catalyst, BPH, was synthesized directly [13] and diaminodiphenylmethane (DDM, supplied by Aldrich Chem. Co.) was selected as a hardener for the curing. Methyl ethyl ketone was used to reduce the high viscosity of DGEBA. Chemical structures of the BPH and DDM used as curing agents are shown in Fig. 1.

Unidirectional composite laminates were prepared by continuous impregnation of the fibers using a drum winding technique for manufacturing prepregs with subsequent hot pressing. The laminates made with 32 plies of prepregs were fabricated in a hot-press at $7.4 \mathrm{MPa}$ at $150^{\circ} \mathrm{C}$ for $150 \mathrm{~min}$ with a vacuum bagging method in a conventional composite processing [14].

To obtain an average fiber volume fraction, $V_{f}$ of the composites, a small size rectangular specimen was cut from the laminate, and the side section of the specimen was polished. The number of fibers $(N)$ was counted using video images of a small area (S) of $1 \mathrm{~mm}$ (thickness direction) $0.2 \mathrm{~mm}$ (width direction), and the average diameter $\left(\mathrm{d}_{\mathrm{f}}\right)$ of the fiber was measured at the cross-section. Average fiber volume fraction $V_{f}$ was then calculated from Eq. (1):

$$
V_{f}=\frac{N \cdot d_{f}^{2} \cdot \pi}{4 S}
$$

The average fiber volume fraction of bulk specimens was about $52 \%(0.2 \%)$ for all composites.

\subsection{Measurements}

Latent properties of the $\mathrm{BPH}$ catalyst used were determined by the measurement of conversion as a function of curing time using the isothermal differential scanning calorimetry (DSC, Perkin Elmer Co., DSC-7) method. ILSS of the composites was conducted by a three-point short-beam bending test method to estimate the interfacial adhesion strength of the composites, according to the ASTM D 2344. The distance between supports divided by the thickness of specimens, $\mathrm{L} / \mathrm{d}=5$, and the crosshead speed was fixed at $2.0 \mathrm{~mm} / \mathrm{min}$. For a rectangular cross section of the composites, the ILSS was calculated as [15]:

$$
I L S S=\frac{3 P}{4 b d}
$$

where $P$ is the load at moment of break, $b$ the width of the specimen, and $d$ the thickness of the specimen.

The accuracy and range of the load cell used were $0.5 \%$ grade and $5 \mathrm{kN}$, respectively. The composites were machined along the fiber direction into $30 \mathrm{~mm} \times 6 \mathrm{~mm}$ short-beam-shear specimens with $5 \mathrm{~mm}$ thickness. The distance between supports divided by the thickness of specimens, $\mathrm{L} / \mathrm{d}=5$, and the cross-head speed was fixed at $2.0 \mathrm{~mm} / \mathrm{min}$. The fracture toughness parameter, critical stress intensity factor $\left(\mathrm{K}_{\mathrm{IC}}\right)$ and specific fracture energies $\left(\mathrm{G}_{\mathrm{IC}}\right)$ of the composites may be characterized by single edge notched (SEN) test in three-point flexure. For the SEN beam fracture toughness test, the value of $\mathrm{K}_{\mathrm{IC}}$ is calculated as follows:

$$
K_{I C}=\frac{P \cdot L}{b \cdot d^{3 / 2}} \cdot Y
$$

where $P$ is the rupture force, $L$ the span between the supports, $Y$ the geometric factor according to the ASTM E399, and $b$ and $d$ the specimen width and thickness, respectively.

Based on the Griffith-Irwin equation [16] the resistance to crack propagation $\left(\mathrm{G}_{\mathrm{IC}}\right)$, or specific fracture energy is increased as the fracture toughness and the poisson ratio increases or as the electric modulus decreases, as follows:

$$
G_{/ C}=\frac{\left(1-v^{2}\right) K_{/ C}^{2}}{E}
$$

where $E$ is the Young)s modulus and $v$ the poisson ratio (0.3) of the carbon fibers.

Notches were cut using a diamond-coated saw, approximate- 
ly half the depth of the specimen. The three-point bending test was conducted using an Instron Model 1125 mechanical tester according to the ASTM E-399. A span-to-depth ratio of 4:1 and cross-head speed of $1 \mathrm{~mm} / \mathrm{min}$ was used. Impact strength was obtained with a Tinius Olsel Model 66 Izod Impact Tester according to ASTM method D790. The morphology of the composites was examined with scanning electron microscope (SEM, JEOL Model $840 \mathrm{~A})$. A small section of the non-woven mat was placed on the SEM sample holder and sputter-coated with gold (Denton Desk1 Sputter Coater). An Amray 3000 SEM using an accelerating voltage of $20 \mathrm{kV}$ was employed to take the SEM photographs.

\section{Results and Discussion}

Fig. 2 shows the conversion of neat epoxy matrix resins cured by BPH and DDM as a function of curing temperature using a dynamic DSC method. The conversions of all compositions are activated at a given specific temperature. However, for the DDM curing agent, the conversion is activated at a lower temperature, resulting in a poor pot-life under room temperature condition. On the other hand, the conversion using the BPH presents a significant change in a specific temperature region as the reaction temperature increases. So, the presence of BPH used as a curing agent appears to support its possible use as a latent thermal initiator in this matrix system, in a given temperature condition.

Fig. 3 shows the results of ILSS, $\mathrm{K}_{\mathrm{IC}}, \mathrm{G}_{\mathrm{IC}}$, and impact strength of the composites. The results clearly indicate that the mechanical property values in composite specimens cured by BPH are higher than those of the ones cured by DDM. As mentioned above, this can be explained as probably due to the effect of the substituted benzene group, resulting in improvement of the ductile fracture properties, leading to the increased good resistance to deformation and crack initiation of the epoxy matrix system in carbon fibers-reinforced composites $[17,18]$. And a good agreement can be found by SEM pictures of the fracture surfaces after impact test, as seen in Fig. 4.

Consequently, the chain segments of the BPH-cured composite system responsible for entanglements and intermolecular interactions, such as hydrogen bonding and double helical formations, mostly exist as the outer bulk side chains which is related to the free volume, including the hydroxyl groups of the epoxy

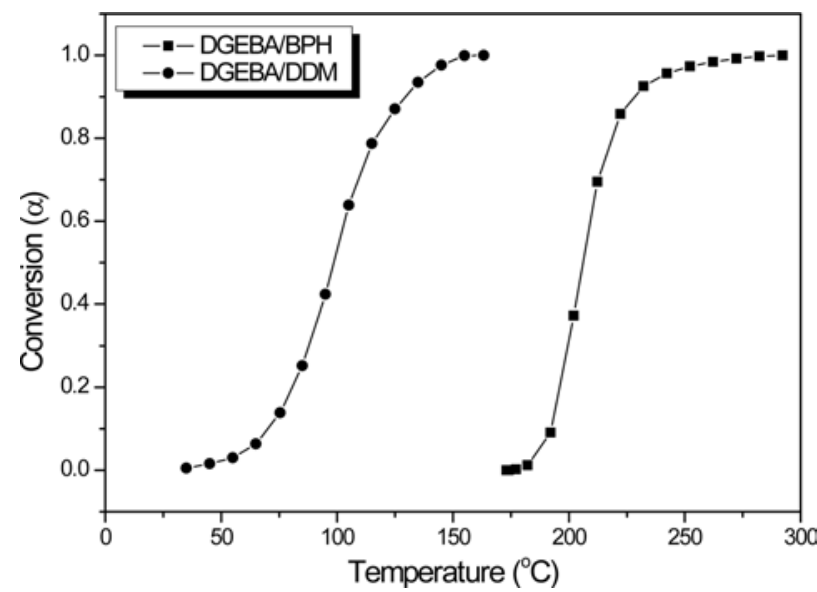

Fig. 2. Conversion of epoxy matrix resins with curing agents i.e., BPH and DDM as a function of curing temperature. BPH: N-benzylpyrazinium hexafluoroantimonate, DDM: diaminodiphenyl methane.
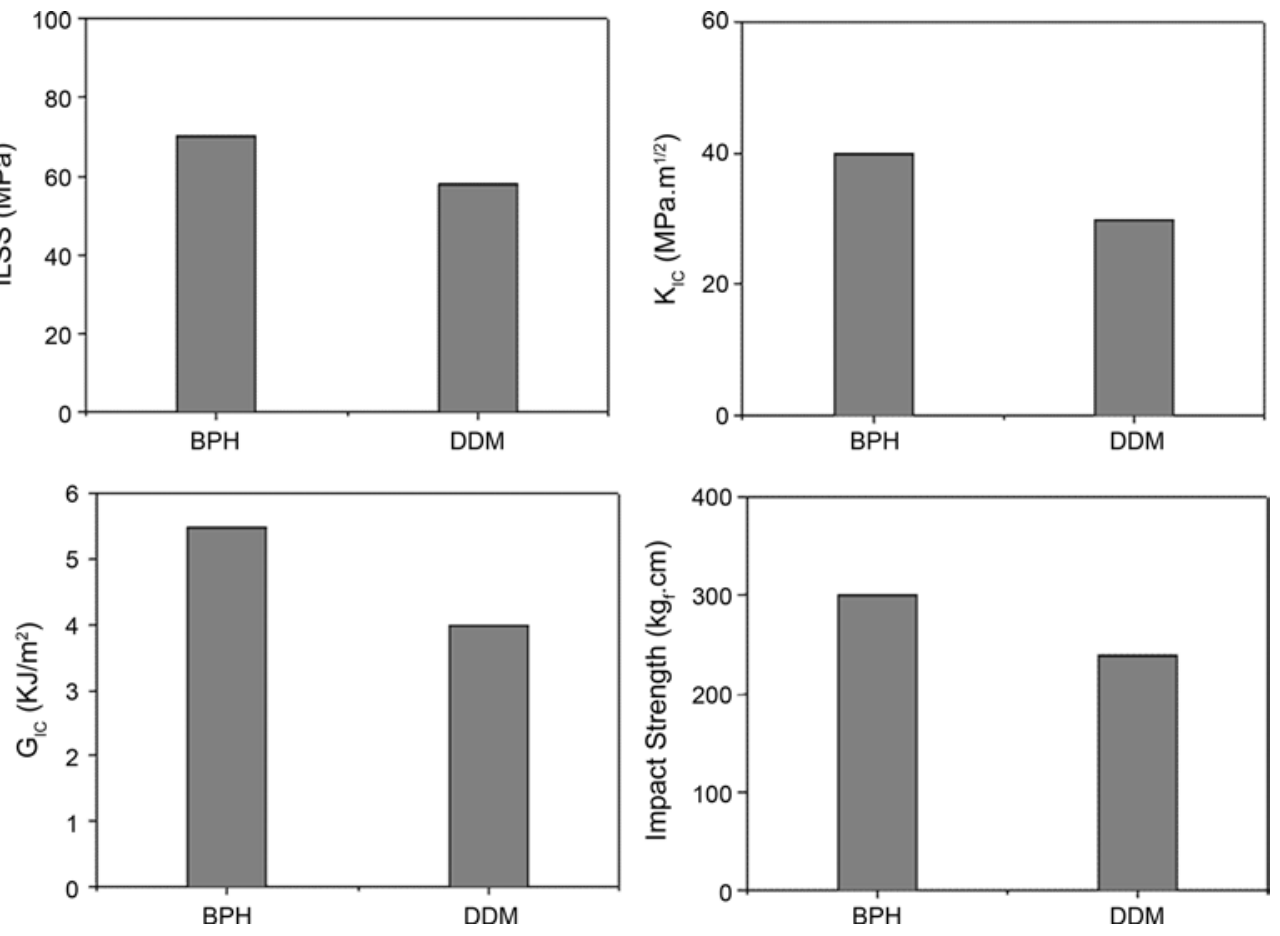

Fig. 3. Mechanical properties of carbon fibers-reinforced epoxy matrix composites. 


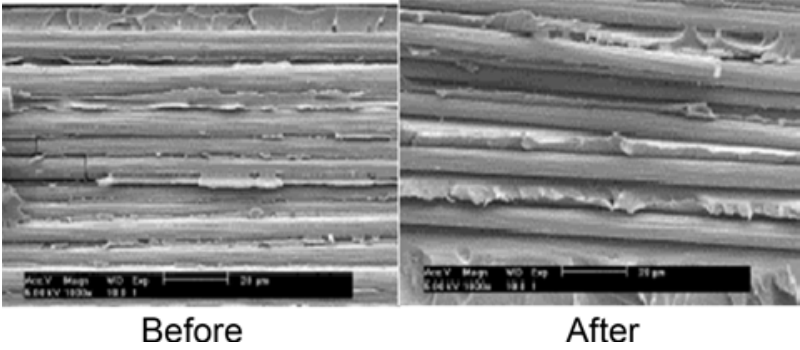

Fig. 4. Scanning electron microsscope pictures of carbon fibersreinforced epoxy matrix composites after impact test.

matrix system. Thus, the chain segments toughen the three-dimensional structure and consequently disperse the internal stress [19], which results in an increase of the elastic modulus in the fracture of the composite system cured by $\mathrm{BPH}$.

\section{Acknowledgements}

This research was supported by a research fund of Jeonju National University of Education 2010.

\section{References}

[1] Inoue S, Aida T. Ring-opening polymerization, McGraw-Hill, New York (1967).

[2] Lee SD, Takata T, Endo T. Arenesulfonates as non-salt-type latent thermal initiators for cationic polymerization. Macromolecules, 29, 3317 (1996). http://dx.doi.org/10.1021/ma9508131.

[3] Abu-Abdoun II, Aale A. Cationic photopolymerization of cyclohexene oxide. Eur Polym J, 28, 73 (1992). http://dx.doi.org/http:// dx.doi.org/10.1016/0014-3057(92)90239-X.

[4] May CA. Epoxy resins: chemistry and technology, 2nd ed., Marcel Dekker, New York (1988)

[5] Crivello JV, Lam JHW. Photoinitiated cationic polymerization by dialkyl-4-hydroxyphenylsulfonium salts. J Polym Sci A, 18, 1021 (1980). http://dx.doi.org/10.1002/pol.1980.170180321.

[6] Gu J, Narang SC, Pearce EM. Curing of epoxy resins with diphenyliodonium salts as thermal initiators. J Appl Polym Sci, 30, 2997 (1985). http://dx.doi.org/10.1002/app.1985.070300722.
[7] Lee H, Neville K. Handbook of epoxy resins, McGraw-Hill, New York (1967)

[8] Senturia S, Sheppard N Jr. Dielectric analysis of thermoset cure. In: Dusek K, ed. Epoxy resins and composites IV, Advances in Polymer Science Vol. 80, Springer, Berlin, 1 (1986). http://dx.doi. org/10.1007/3-540-16423-5 11.

[9] Lee SB, Takata T, Endo T. ( $\rho$-Methoxybenzyl)- and ( $\alpha$-methylbenzyl)- $\rho$-cyanopyridinium hexafluoroantimonates: activated latent thermal catalysts. Macromolecules, 23, 431 (1990). http://dx.doi.org/10.1021/ma00204a014.

[10] Park SJ, Seo MK, Lee JR. Isothermal cure kinetics of epoxy/ phenol-novolac resin blend system initiated by cationic latent thermal catalyst. J Polym Sci A, 38, 2945 (2000). http:// dx.doi.org/10.1002/1099-0518(20000815)38:16<2945::AIDPOLA120>3.0.CO;2-6.

[11] Reich B. Reliability of plastic encapsulated semiconductor devices and integrated circuits. Solid State Technol, 21, 82 (1978).

[12] Melliar-Smith CM, Matsuoka S, Hubbauer P. Plastic encapsulation of silicon integrated circuits, Plast Rubber Mater Appl, 5, 49 (1980).

[13] Park SJ, Seo MK, Lee JR, Lee DR. Studies on epoxy resins cured by cationic latent thermal catalysts: the effect of the catalysts on the thermal, rheological, and mechanical properties. J Polym Sci A, 39, 187 (2001). http://dx.doi.org/10.1002/10990518(20010101)39:1<187::AID-POLA210>3.0.CO;2-H.

[14] Seo MK, Park SJ. Influence of oxyfluorination on physicochemical characteristics of carbon fibers and their reinforced epoxy composites. Macromol Res, 17, 430 (2009). http://dx.doi.org/10.1007/ BF03218885.

[15] Park SJ, Seo MK. Interface science and composite, Interface science and technology Vol. 18, Elsevier, Amsterdam (2011).

[16] Griffith AA. The phenomena of rupture and flow in solids. Phil Trans R Soc Lond A, 221, 163 (1921). http://dx.doi.org/10.1098/ rsta.1921.0006.

[17] Lee JH, Lee JS, Rhee KY. Effects of oil absorption on the wear behaviors of carbon/epoxy woven composites. Carbon Lett, 12, 249 (2011). http://dx.doi.org/10.5714/CL.2011.12.4.249.

[18] Morgan P. Carbon fibers and their composites. Taylor \& Francis, Boca Raton (2005).

[19] Dowling NE. Mechanical behavior of materials: engineering methods for deformation, fracture, and fatigue. Prentice Hall, Englewood Cliffs (1993). 